\title{
Scab Disease Caused by Venturia inaequalis on Apple Trees in Kyrgyzstan and Biological Agents to Control This Disease
}

\author{
Tinatin Doolotkeldieva, Saykal Bobusheva \\ Plant Protection Department, Faculty of Agriculture, Kyrgyz-Turkish Manas University, Bishkek, Kyrgyzstan \\ Email: tdoolotkeldieva@gmail.com
}

How to cite this paper: Doolotkeldieva, T. and Bobusheva, S. (2017) Scab Disease Caused by Venturia inaequalis on Apple Trees in Kyrgyzstan and Biological Agents to Control This Disease. Advances in Microbiology, 7, 450-466.

https://doi.org/10.4236/aim.2017.76035

Received: May 1, 2017

Accepted: June 12, 2017

Published: June 15, 2017

Copyright ( 92017 by authors and Scientific Research Publishing Inc. This work is licensed under the Creative Commons Attribution International License (CC BY 4.0).

http://creativecommons.org/licenses/by/4.0/

\begin{abstract}
Among the most economically important fruit crops in South and North Kyrgyzstan affected by scab disease are apples (Malus domestica). Natural isolates of Venturia inaequalis were isolated from diseased parts of apple trees, selected from different regions, through sedimentation of air microflora on the crowns of fruit trees. Two biocontrol agents as Trichoderma viride and Streptomyces sp. were tested for apple scab control in vitro and field conditions. Two applications of Trichoderma viride within 35 days completely stopped the scab disease in seedling leaves. Within 40 days, the seedlings were recovered; the new leaves have blossomed on branches. The Streptomyces sp. antagonists were inferior in effectiveness compared to Trichoderma viride; nevertheless, they prevented progression of the disease in the leaves. Seedlings grew new shoots and leaves around 50 days after the second treatment. Orchard experiment results provide great hope that a biological product based on Trichoderma viride could work as an effective agent to suppress the development of the pathogen in the early spring, when leaves start to show scab disease symptoms.
\end{abstract}

\section{Keywords}

Apple Scab, Venturia inaequalis, Trichoderma viride, Streptomyces sp., Biological Control

\section{Introduction}

Among the economically most important fruit crops in South and North Kyrgyzstan affected by scab disease are apples (Malus domestica). In 2015, 16,189 hectares of gardens in Kyrgyzstan were surveyed, of which 4643 hectares were infected by scab disease. During the most intensive development period, this 
disease affected 5\% - 55\% of trees and 1\% - 56\% of their fruits; 1267 hectares of garden were treated by chemical fungicides [1]. According to some data, up to 20 fungicide treatments are applied per season to control the disease [2] [3].

Venturia inaequalis (Cooke Wint) is the causal agent, affecting the leaves and fruit tissue of trees. The pathogen was placed into the genus Venturia by Winter in 1880. These historical accounts and the genus' taxonomy have been reviewed by MacHardy [4]. V. inaequalis is a heterothallic fungus and contains seven haploid chromosomes [5]. It leads both a saprophytic (marsupial stage Venturia inaequalis (Cke)) and parasitic (imperfect stage Fusicladium dendriticum ( Wallr) Fuck) lifestyle. The causal agent overwinters in infected fallen leaves. In the spring, it enters a marsupial stage in the form of small black tubercles-pseudothecium (typical fruiting bodies), within which ascospores mature [6] [7] two unequal-sized cells, with a thin, brittle outer wall and a thick, elastic inner wall which assists the persistence of the pathogen during winter [4].

In the presence of moisture, the pathogen ascospores germinated on the leaves, breaking the thin surface epithelium of young leaves. Upon contact with a cuticle, the germ tube is differentiated into an appressorium and produces adhesive mucilaginous substances, assumed to be used to facilitate attachment to the host surface [8]. The mucilaginous substances are composed of proteins and carbohydrates such as $\beta$-galactose and $\mathrm{N}$-acetylglucosaminyl residues [9]. Once infected, a fungal mycelium develops between epithelium and leaf epidermis. Furthermore, there is a rupture of the epithelium under pressure from the developed mycelium and numerous conidiophores on short conidiophores (imperfect stage) that are formed. At this time, outward signs of the disease are usually detected. Diseased leaves first appear translucent, like oil, before greying spots appear, with a characteristic greenish brown (dark olive), velvety trace of conidial sporulation of fungus [10]. This completes the first cycle of infection, which lasts an average of about two weeks.

Then, an intermittent cycle of secondary infections can begin, through newly developing conidiophores. As a rule, after secondary and third infections, scab disease reaches maximum intensity. Further development of the disease depends on atmospheric humidity. Summer drought suppresses the development of scab disease; conidiophores quickly lose their ability to germinate and infect the leaves. Full development of the parasitic phase scab pathogen ends with the cessation of growth of the apple trees, when the leaves are falling and the fungus again enters a saprophytic way of life. Weather conditions-temperature and humidity in particular-are important for the development of apple scab disease, especially in the first half of the growing season [5]. After the germination period, $V$. inaequalis infects the leaf by penetrating the cuticle and establishing a primary stroma between the cuticle and the epidermis of the leaf.

Once an infection is established, curative preparations are required to stop further development of the mycelium. In organic apple-growing, scab disease control is focused on the protective use of sulphur, lime sulphur and copper. 
Additional sprays of lime sulphur during the germination period of the scab fungus are applied during severe infection periods. These specific applications are difficult to schedule, as the time period for the application is often short and in most cases these sprays have to be performed during rainfall and at night [11]. The control of scab infections on apple leaves and fruits is usually done by the conventional use of synthetic fungicides. Different compounds based on carbonates have been tested for apple scab control during previous years, resulting in variable efficacies [12] [13] [14]. This can be explained by the influence of different formulations used, different weather conditions or by the timing of the application, which has a considerable impact on the efficacy. Alternative approaches to chemical use are highly appreciated due to the increasing importance of integrated management strategies relying on biocontrol, possibly combined with selective application of fungicides [15]. The above strategies must meet two requirements: effectiveness and environmental safety. Regarding the group of interesting biocontrol agents that can be involved in integrated management strategies; the antagonistic fungi are considered the most promising agents, currently being developed as a novel approach for the control of many plant diseases [16].

Pseudomonas syringae (isolate 508) prevented spore germination and effectively suppressed scab disease to a level comparable to that provided by the fungicide, captan. This isolate provided greater suppression of apple scab disease than did other pathogenic isolates of $P$. syringae, isolated from various crops [17].

Objectives of our study were 1) to study the biology and spread of $V$. inaequalis on apple trees, 2) to select possible antagonists to suppress sporulation of the pathogen, 3) to test selected antagonists under field conditions.

\section{Methods and Materials}

\subsection{Sampling for the Isolation of the Pathogen}

The diseased organs (leaves, shoots, buds and fruits) of different varieties of apple (Malus domestica M.) were selected in the orchards and fruit farms of the Chui and Issyk-Kul provinces (Table 1) to isolate a pure culture of scab disease

Table 1. Samples taken from diseased plants.

\begin{tabular}{cccc}
\hline Time of sampling & Sampling place & Species of plants & Plant organs \\
\hline $\begin{array}{c}\text { The end of April and } \\
\text { May, 2014 and } 2015\end{array}$ & $\begin{array}{c}\text { Botanical garden } \\
\text { named after Gareev, } \\
\text { the city of Bishkek }\end{array}$ & $\begin{array}{c}\text { Different varieties } \\
\text { of apples }\end{array}$ & $\begin{array}{c}\text { Young buds; leaves } \\
\text { with symptoms }\end{array}$ \\
The end of May, 2014 and & $\begin{array}{c}\text { Orchards of } \\
\text { Issyk-Kul } \\
\text { province }\end{array}$ & $\begin{array}{c}\text { Different varieties } \\
\text { of apples }\end{array}$ & $\begin{array}{c}\text { Young buds; leaves } \\
\text { with symptoms }\end{array}$ \\
& $\begin{array}{c}\text { Orchards of } \\
\text { September-October, 2015 }\end{array}$ & Young nursery & Affected shoots and \\
& provinces & lef apple varieties & leaves \\
\hline
\end{tabular}


pathogen (Venturia inaequalis (Cooke) Wint).

A sample consisted of different plant parts selected from one tree. Each sample contained at least five copies of plant parts with disease symptoms (the affected leaves, ovary, young shoots, the slices of damaged tissue branches and trunks), which were placed in a safe package with a label with the name of the culture, varieties, age, place, time of collection and an indication of the type of lesion.

\subsection{Extraction of Pathogen Cells by Shaking in a Buffer}

Samples were placed in a $150 \mathrm{ml}$ container with a lid, before a $30 \mathrm{ml}$ phosphate buffer or phosphate-buffered saline was added. The container was placed on a rotary shaker and then incubated at $200 \mathrm{rev} / \mathrm{min}$ from 1.0 to 1.5 hours. For samples with symptoms, the appropriate amount of macerate was selected for qualifying analysis. For asymptomatic samples, a suspension concentrated by centrifugation was used. The sample was also frozen at $-18^{\circ} \mathrm{C}$. Macerate was carefully poured directly into a $50 \mathrm{ml}$ centrifuge tube, leaving the pulp in a container or pre-filtered through filter paper, then centrifuged for 10 minutes at $8000 \mathrm{~g}$ and for 15 minutes at an acceleration of $7000 \mathrm{~g}$, at a temperature below $10^{\circ} \mathrm{C}$. The supernatant was discarded without damaging the sediment. The pellet was resuspended in $1 \mathrm{ml}$ of phosphate buffer and transferred to a sterile microtube.

\subsection{Isolation of a Pure Venturia inaequalis Culture}

The following culture media were used for the primary isolation of scab pathogens:

1) Potato agar (g/distilled water): potatoes $-200 \mathrm{~g}$; Agar-15 g; water-1 L; $\mathrm{pH}-6.2$;

2) Apple agar: chopped apple fruit weight-200 g; Agar-15.0; water-1 L; $\mathrm{pH}-6.5$;

3) Czapek's medium; $\mathrm{pH}-6.2$;

4) Wort agar: wort- $50 \mathrm{ml}$; agar-20 g; water-1.0 L; $\mathrm{pH}-6.5$.

A special technique was used to determine the morphological features of Venturia inaequalis proposed by [18] [19] for other fungi. This technique is simple, cheap and does not require much time. It analyses the following morphological features: the size of spores, the diameter of the hyphae and culture function; the growth of the colonies and the colour of the pathogen colonies were studied accurately.

\subsection{Sources of Antagonists}

Biocontrol antagonistic microorganisms (Streptomyces and Trichoderma) from our laboratory collection were used in this study.

\subsection{In Vitro Determination of Antibiotic Activity of Antagonistic Microorganisms against Scab Disease Pathogens}

N.S. Egorov's [20] perpendicular stroke method was used. The antagonist cul- 
ture was plated on the diameter of Petri dishes and after four to five days, test cultures (Venturia inaequalis) were plated.

Also, the agar blocks method was used. Biocontrol antagonistic microorganisms (Streptomyces and Trichoderma) were plated onto the surface of the agar medium, formed during the growth of a continuous lawn in a Petri dish. Cultures are incubated at a suitable temperature for four to five days. Then, a sterile cork drill ( 6 - $8 \mathrm{~mm}$ diameter) was cut from the layer agar blocks and transferred to the surface of the agar medium, inoculated only that the test organism (Venturia inaequalis). Agar blocks were placed in increasing (lawn) up at an equal distance from each other and from the edge of the cup, connected tightly to the agar plate.

\subsection{Screening the Antibiotic Activity of Antagonistic Microorganisms against Scab Pathogens on Apple Seedlings}

The potential of candidate antagonists to suppress the conidia production of Venturia inaequalis on infected leaves was tested on the local "Aychurok" variety of apple seedlings, highly susceptible to scab disease. Seedlings were sprayed with conidial suspensions of Venturia inaequalis $\left(1 \times 10^{5} \mathrm{ml}^{-1}\right)$ until runoff and placed in a moist chamber consisting of a plastic tray enclosed by a transparent plastic top. After two days of incubation at $15^{\circ} \mathrm{C}$ with diffuse light, the tops were removed from the trays and seedlings were further incubated for five days at $85 \% \mathrm{RH}, 15^{\circ} \mathrm{C}$ and with $16 \mathrm{hrs}$ light per day. Thereafter, $V$. inaequalis-inoculated seedlings were sprayed with antagonist suspensions (containing $1 \times 10^{6}$ spores or cells $\mathrm{ml}^{-1}$ ) or water (containing $0.01 \%$ Tween 80 ) as control. Two seedlings were used for each replicate of each treatment. Touching of leaves of neighbouring plants or the polyethylene was avoided. Seedlings were grown for nine to 12 days at $15^{\circ} \mathrm{C}$, with $16 \mathrm{hrs} \mathrm{light} \mathrm{per} \mathrm{day} \mathrm{at} 138 \mu \mathrm{E} \cdot \mathrm{s}^{-1} \cdot \mathrm{m}^{-2}$. From both seedlings of each replicate, the youngest five true leaves were carefully removed and put into Duran bottles $(100 \mathrm{ml})$ containing $35 \mathrm{ml}$ of tap water with $0.01 \%$ Tween 80. Bottles were shaken with a flask shaker and the concentration of conidia of $V$. inaequalis was determined for each suspension with the aid of a haemocytometer [21].

\subsection{Orchard Experiments}

Two rows of three-year-old apple trees of the Aychurok variety were used to test the antagonists in the Plant Research field at the Agriculture Faculty, KTU Manas, and Bishkek. For each experiment, two to four trees in two replicates were used. Within each replicate, two treatments were carried out.

\subsection{Statistical Analysis}

Data were analysed following the GLIM program of the Royal Society of London [22]. Significant differences between the two mean values, due to different treatments or varieties and their interaction at a crop growth stage were computed by comparing their significant levels at $\mathrm{P}<0.05$. 


\section{Results and Discussion}

The scab pathogen infection cycle begins in spring, when appropriate temperature and humidity promote the release of ascospores. These spores are released into the air, on the ground and onto the surface of the sensitive tree, where they germinate and form a germ tube that can directly penetrate the waxy cuticle of the plant. Natural isolates of Venturia inaequalis were isolated by sedimentation of air microflora on the crown of fruit trees in April.

The cultural and physiological characteristics of the selected natural isolates were studied on the Czapek's agar, the apple agar and wort agar mediums and incubated at a temperature of $18^{\circ} \mathrm{C}-28^{\circ} \mathrm{C}$. A rapid growth of pathogen colonies on the first day was observed in apple agar. Young colonies were fluffy, light brown in colour, growing on the radial radiant. With maturation, the colony colour changed to milky brown and the texture also changed; it became more homogeneous and dense. The microscopy has shown that the colonies growing on apple fruits are thin, with a pale yellow septate mycelium and oval/round conidia, transparent and pale yellow in colour. The conidiophores had interwoven to form clusters. This is the pathogen's asexual reproduction stage, i.e., conidia generation continues throughout the summer, until the fall of the tree leaves and fruits at the beginning of winter. This cycle is called a secondary infection (Figure 1(a)).

On the second day after planting on the Czapek's medium, isolates of Venturia inaequalis began to grow at high speed. Young colonies were dense, with a cotton-like texture and white in colour, while mature colonies became a darker colour and smoother. Microscopy of the colonies growing on the Czapek's

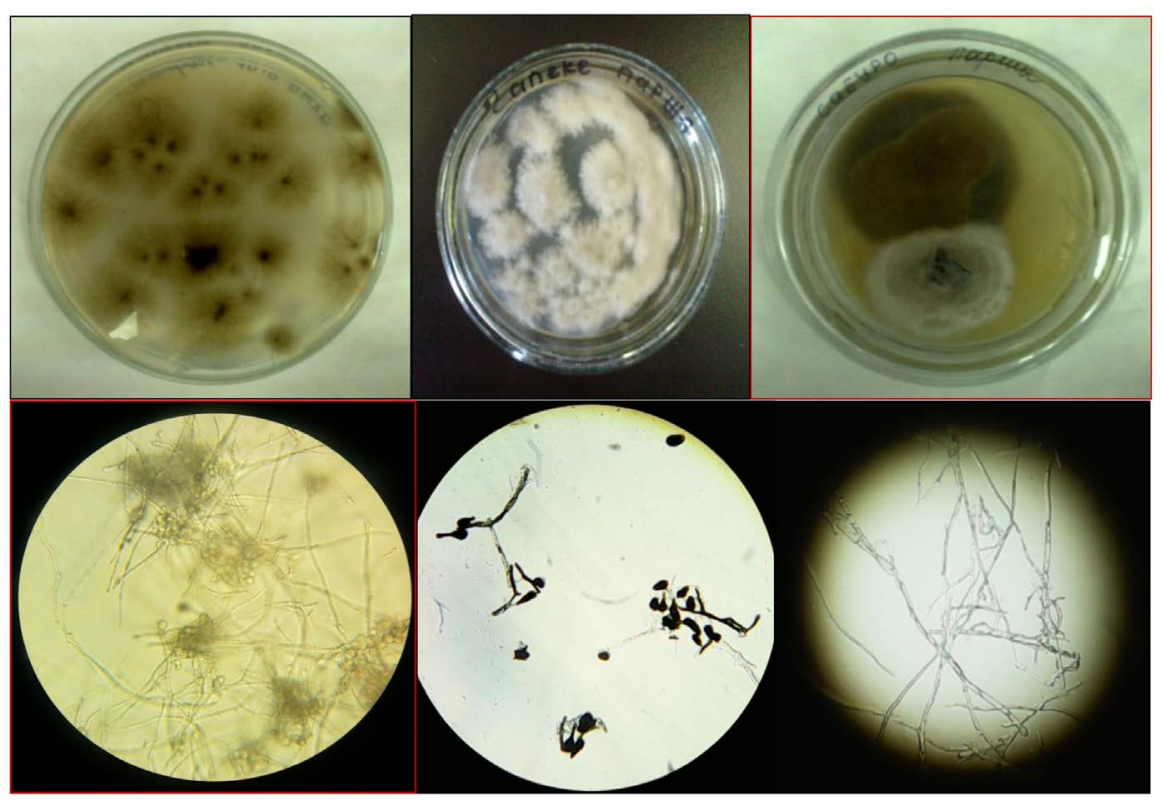

(a) (b) (c)

Figure 1. Cultural characteristics of Venturia inaequalis originally obtained from apple fruit: (a), on apple agar after 24 hours of incubation; (b), on Czapek's medium agar after 48 hours of incubation; (c) on wort medium after 72 hours of incubation. 
medium for three days identified longitudinally extending colourless conidiophores; conidia were dark in colour and oblong-circular in shape (Figure 1(b)).

Venturia inaequalis isolates formed soft, fluffy and thick white colonies on the wort medium. However, compared with the growth on the Czapek's and apple fruit mediums, the wort medium pathogen showed weak growth, although the growth did not stop. Under the microscope, multicellular, thin and colourless mycelium was observed (Figure 1(c)).

\subsection{Biochemical Characteristics of Venturia inaequalis Isolates}

To study the phenotypic characteristics of Venturia inaequalis isolates disaccharides as carbon sources, glucose, cellulose, mannitol and sorbitol were used. Natural isolates of Venturia inaequalis were able to utilize the glucose and cellulose, changing the colour of the liquid medium (with indicator) to red and the mannitol and sorbitol to yellow.

\subsection{Evaluation of the Antagonistic Activity of Actinomycetes Streptomyces and Trichoderma virida against Venturia inaequalis in Vitro}

For the development of environmentally friendly local control measures against scab pathogen of fruit trees, the biotests were conducted using soil actinomycetes and Trichoderma virida against Venturia inaequalis. The following actinomycetes strains were used as antagonists: Streptomyces sp. C1-4; Streptomyces sp. Pr-3; Streptomyces sp. KK-4; Streptomyces sp. K-4; Streptomyces sp. K-7; Streptomyces sp. SK-3.3, Streptomyces sp. PAT-3. Antagonist activity is measured by size of the lysis zones of the test object in $\mathrm{mm}$ (Figure 2).

As the results have shown, the antagonistic activity of Streptomyces strains against Venturia inaequalis was different. The C1-4 strain showed a strong antifungal effect against the phytopathogens; a lysis zone was $10.0 \mathrm{~mm}$ after 96 hours.

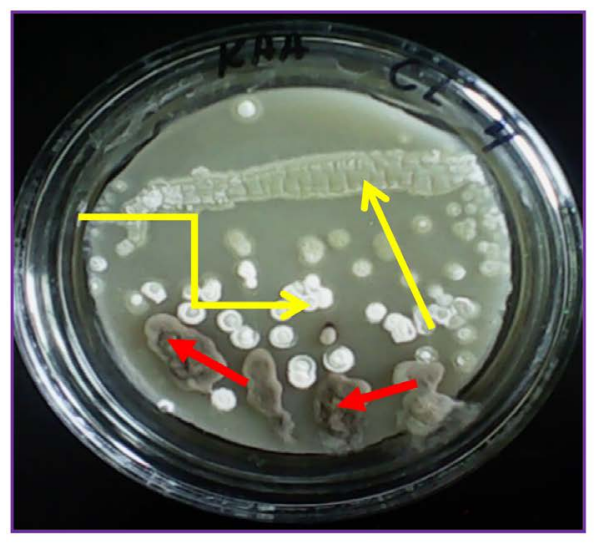

(a)

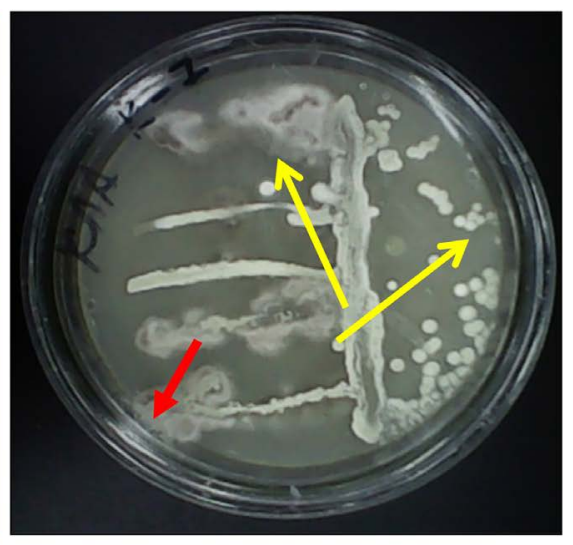

(b)

Figure 2. (a) Inhibition of growth of Venturia inaequalis colonies under the antagonistic activity of Streptomyces sp. C1-4; (b) Hyper-parasitism activity of Streptomyces sp. PAT3 on Venturia inaequalis. Yellow arrows indicate the colonies of Streptomyces sp., while red arrows indicate Venturia inaequalis colonies. 
The Streptomyces strains, such as PAT-3 and Pr-3, inhibited the growth of the pathogen culture, using its colonies as a source of nutrients. Other strains, such as Streptomyces $K K-4, K-4$ and $S K-3.3$ were not active against Venturia inaequalis (Table 2).

Two strains (Streptomyces sp. C1-4 and Streptomyces sp. PAT-3) with strong antagonistic and hyper-parasitic effects were selected for the experiment in a liquid medium. A liquid culture of these antagonists was cultivated with Venturia inaequalis for 48 hours.

The microscopy study of a liquid culture showed a clear picture of the destruction of plant pathogenic conidia and conidiophores, as well as, attached to them, the branched mycelium and spores of antagonists-Streptomyces. The hyper-parasitism mechanism is accurately tracked through these micro-pictures (Figure 3).

\subsection{Screening of Antagonistic Microorganisms on Seedlings}

Five days after artificial infection of highly susceptible apple seedlings of the local "Aychurok" variety, the first symptoms of the disease emerged on the youngest leaves: oil spots on the leaves' surfaces. After seven days, necrotic or chlorotic lesions were noted on the edges of the leaves (Figure 4).

Table 2. Antagonistic activity of Streptomyces and Trichoderma strains against Venturia inaequalis.

\begin{tabular}{|c|c|c|c|c|}
\hline \multirow{2}{*}{$\begin{array}{c}\text { The } \\
\text { antagonistic } \\
\text { strains }\end{array}$} & \multicolumn{4}{|c|}{ Activity, lysis zone, mm } \\
\hline & $24 \mathrm{~h}$ & $48 \mathrm{~h}$ & $72 \mathrm{~h}$ & $96 \mathrm{~h}$ \\
\hline $\begin{array}{c}\text { Streptomyces sp. } \\
\qquad 1-4\end{array}$ & $0.3 \pm 0.01$ & $0.5 \pm 0.02$ & $0.8 \pm 0.02$ & $10.0 \pm 0.02$ \\
\hline $\begin{array}{c}\text { Streptomyces sp. } \\
\qquad \operatorname{Pr}-3\end{array}$ & $0.1 \pm \quad 0.01$ & $0.1 \pm 0.01$ & $0.3 \pm 0.01$ & Hyper-parasitism \\
\hline $\begin{array}{c}\text { Streptomyces sp. } \\
K K-4\end{array}$ & $\begin{array}{c}\text { The force between } \\
\text { two cultures is } \\
\text { equal }\end{array}$ & $\begin{array}{c}\text { The force between } \\
\text { two cultures is } \\
\text { equal }\end{array}$ & $\begin{array}{c}\text { The force between } \\
\text { two cultures is } \\
\text { equal }\end{array}$ & $\begin{array}{c}\text { The force between two } \\
\text { cultures is equal }\end{array}$ \\
\hline $\begin{array}{l}\text { Streptomyces } \\
\text { sp. K-4 }\end{array}$ & Shows no activity & Shows no activity & Shows no activity & Shows no activity \\
\hline $\begin{array}{c}\text { Streptomyces sp. } \\
K-7\end{array}$ & $0.1 \pm 0.01$ & $0.3 \pm 0.01$ & $\begin{array}{c}\text { The force between } \\
\text { two cultures is } \\
\text { equal }\end{array}$ & $\begin{array}{c}\text { The force between two } \\
\text { cultures is equal }\end{array}$ \\
\hline $\begin{array}{c}\text { Streptomyces sp. } \\
S K-3.3\end{array}$ & $\begin{array}{c}\text { The force between } \\
\text { two cultures is } \\
\text { equal }\end{array}$ & Shows no activity & Shows no activity & Shows no activity \\
\hline $\begin{array}{c}\text { Streptomyces sp. } \\
\text { PAT-3 }\end{array}$ & Strong activity & $0.2 \mathrm{~mm}$ & $0.4 \mathrm{~mm}$ & Hyper-parasitism \\
\hline $\begin{array}{l}\text { Trichoderma } \\
\text { virida }\end{array}$ & Strong activity & Hyper-parasitism & Hyper-parasitism & Hyper-parasitism \\
\hline
\end{tabular}



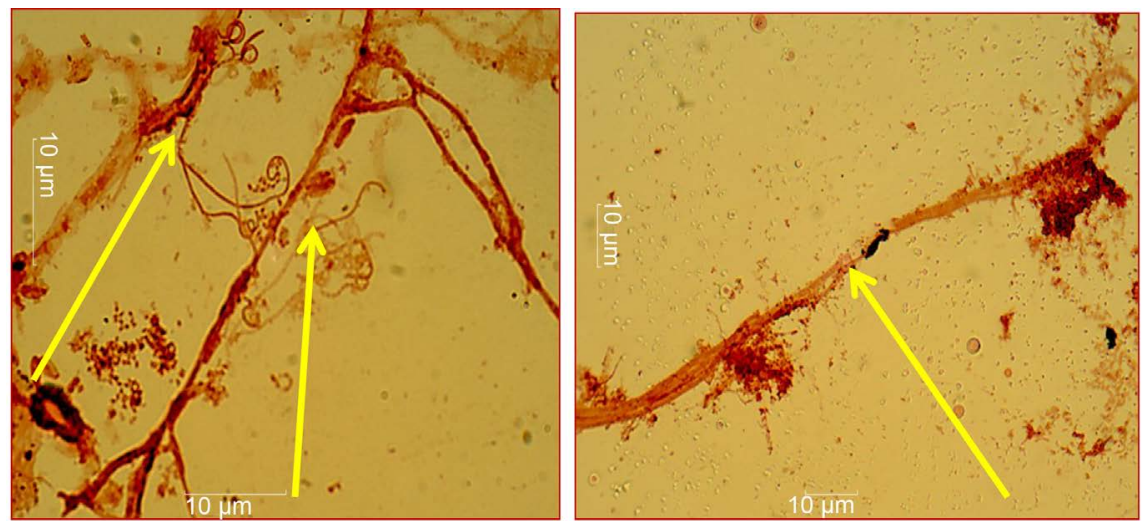

Figure 3. The destruction of the cell wall structure of hyphal bodies and mycelia of the pathogen Venturia inaequalis, when co-cultured with the culture of Streptomyces sp. C1-4 and Streptomyces sp. PAT-3.

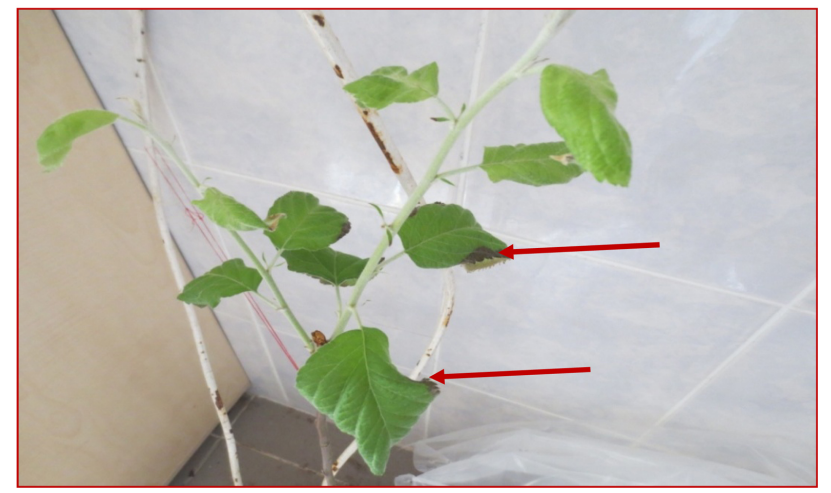

Figure 4. The apple seedlings with disease symptoms on the leaves after spraying with Venturia inaequalis $\left(1 \times 10^{5} \mathrm{ml}^{-1}\right)$ on day seven.

Five leaves from each tree were stripped and placed in $100 \mathrm{ml}$ of sterile water. After shaking for one hour, $1 \mathrm{ml}$ of suspension was planted on the nutrient media. Direct microscopy $(1000 \times)$ of the diseased leaves and the colonies growing on the medium has found mycelium, conidia and conidiophores of the pathogen (Figure 5).

After the appearance of visible signs of the disease, seven days after infection, the seedlings' leaves were abundantly treated with antagonist cultures. Ten days after the first treatment with antagonist cultures, five leaves of the apple seedling were removed for microscopy and planting on the relevant mediums. Pathogen colonies on a single leaf were counted and the average number of colonies was calculated (Figure 6).

As Figure 6 shows, conidia production of $V$. inaequalis on apple leaves has been reduced by up to $50 \%$ five days after treatment with Streptomyces sp. C1-4. After 10 days, it had been reduced by up to $60 \%$ in comparison with the control trees. After 15 days, a second treatment was carried out. On the 25th and 35th days after the second treatment, the number of conidia of the pathogen had been reduced by up to $35 \%$. 


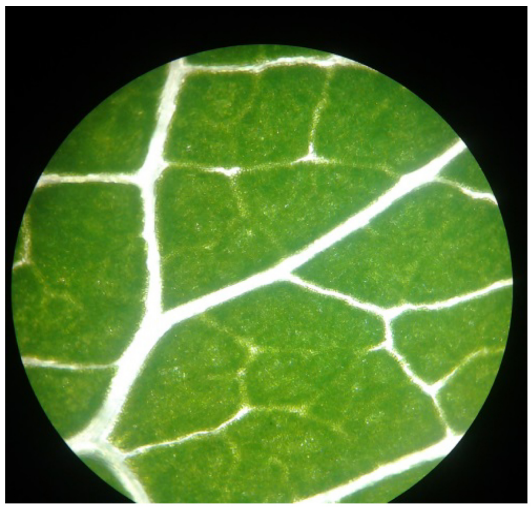

(a)

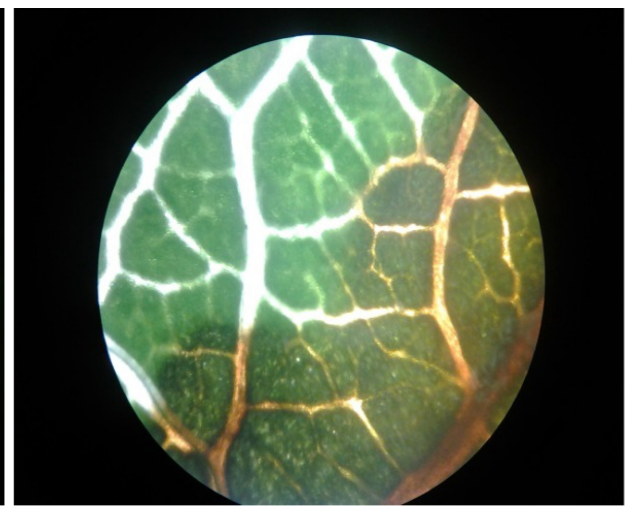

(b)

Figure 5. Direct microscopy $(1000 \times)$ of leaves: (a) Healthy leaf tissue and (b) Diseased leaf tissue with penetrating mycelium of the pathogen.

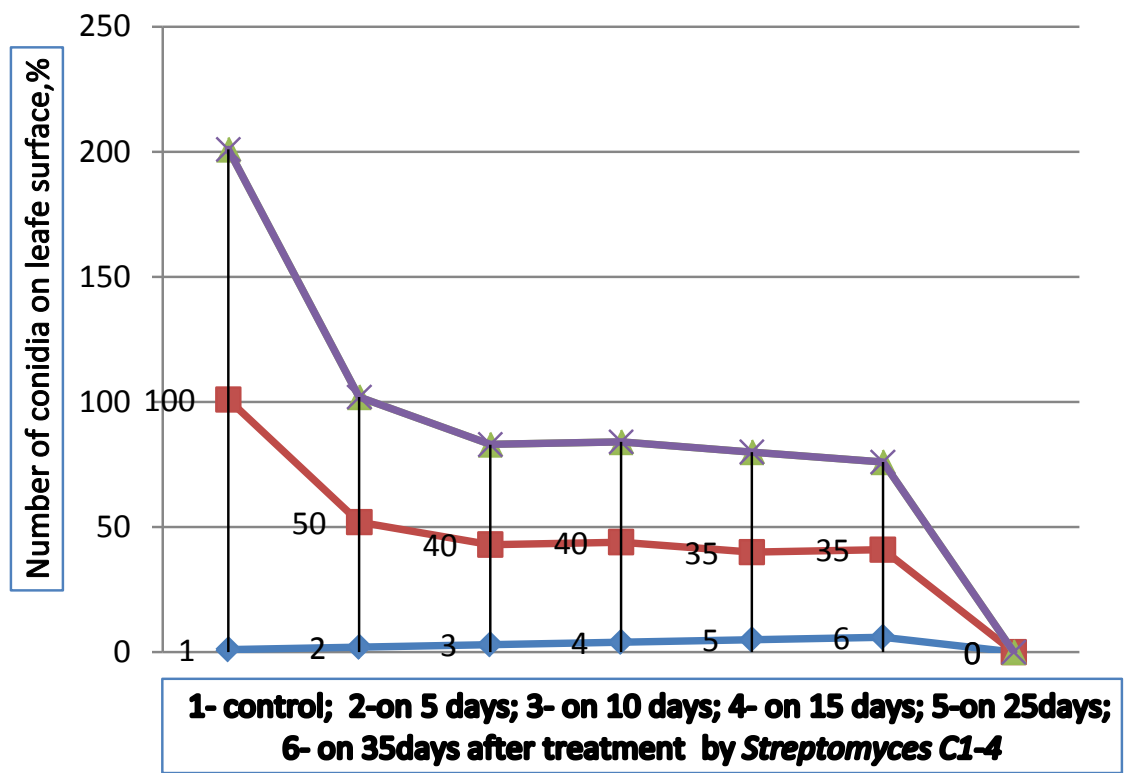

Figure 6. Conidia production of $V$. inaequalis on apple leaves treated twice with Streptomyces sp. C1-4 $\left(1 \times 10^{6}\right.$ spores or cells $\left.\mathrm{ml}^{-1}\right)$.

On the leaves of seedlings which had been sprayed with Trichoderma virida suspension $\left(1 \times 10^{6}\right.$ conidia $\left.\mathrm{ml}^{-1}\right)$, conidia production of the pathogen decreased sharply, up to $30 \%$ after five days, reducing by up to $80 \%$ after 10 days in comparison with control seedlings. After 15 days. a second treatment was carried out. 25 and 35 days after the second treatment the number of pathogen conidia had reduced by up to $90 \%$ and $95 \%$ respectively (Figure 7 ).

There has been a pattern of preventing the progression of the disease caused by $V$. inaequalis. Before the use of antagonists, the diseased seedlings had an average of three to four infected leaves, with either a single necrotic lesion or several lesions scattered over the leaf's surface. After the first and second treatments with Trichoderma virida, the number of infected leaves had not increased and progression of the disease had completely stopped.

When Streptomyces sp. C1-4 was used in some leaves, there was still some 


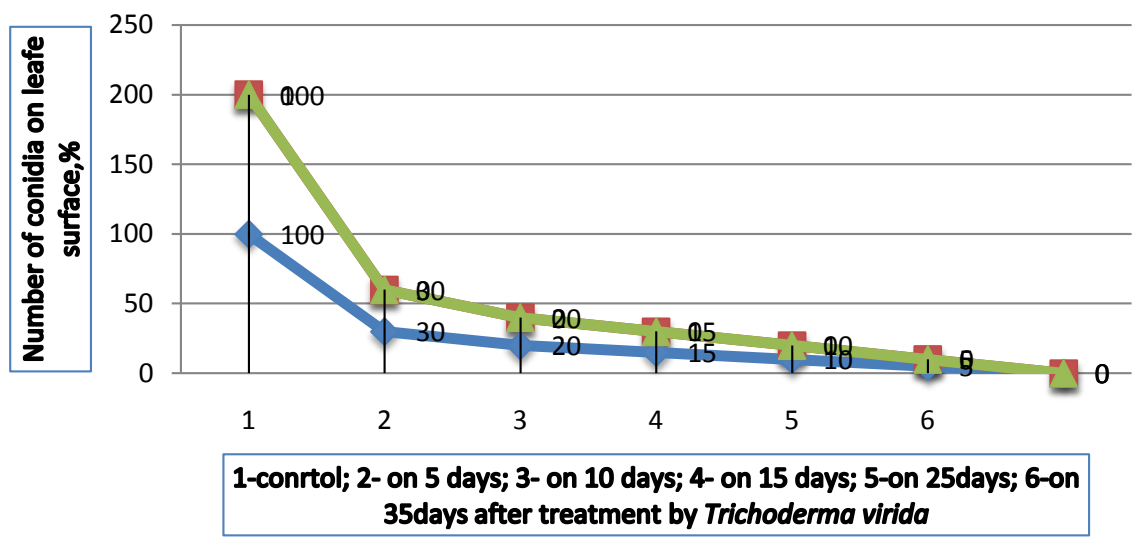

Figure 7. Conidia production of $V$. inaequalis on apple leaves treated twice with Trichoderma virida $\left(1 \times 10^{6}\right.$ spores or cells $\left.\mathrm{ml}^{-1}\right)$.

disease progression. So, while tested Streptomyces sp. C1-4 strains have statistically significantly reduced conidia of $V$. inaequalis, their efficiency was lower than that of Trichoderma virida. Streptomyces sp. $C 1$ strain has caused a significant reduction of $V$. inaequalis on leaves, which could be repeated in subsequent independent experiments.

To determine the shelf life of antagonist spores on the leaf surfaces of seedlings after treatment, the treated leaves of seedlings were removed and relocated to the surface of culture media with outer and inner surfaces. The leaves were treated with Streptomyces sp. C1-4 and planted on an ammonium starch medium (for actinomycetes), while the leaves treated with Trichoderma virida were planted on a Czapek's medium.

The intensity and density of antagonist colonies growing around the leaves in the mediums showed their persistence on leaf surfaces after treatment. The longer they remained on the surface of diseased leaves, the greater their probability of being able to suppress the development of the pathogen.

Results have showed that the conidia of Trichoderma virida were obtained between 10 and 50 days after the second treatment, encouraging intensive growth around the leaves planted on the Czapek's medium (Figure 8). In some dishes, the growth of one to two colonies of the Venturia inaequalis pathogen within the colonies of Trichoderma virida was observed; after a short time, the pathogen colonies were fully covered by colonies of the antagonist (Figure 9). This suggests that the Trichoderma virida has a double effect: as an antagonist and as a hyper-parasite. It could therefore suppress the development of pathogen mycelium on diseased leaves and use them as a nutrient source, producing chitinase and other enzymes that degrade the cell wall of the pathogen mycelium [23].

Due to this effect, two applications of Trichoderma virida within 35 days completely stopped the disease in seedling leaves. After 40 days, the seedlings had recovered, with new leaves and some damaged leaves which remained on the crown continuing to function normally (Figure 10(a)). The Streptomyces sp. antagonists were shown to be inferior in effectiveness compared to Trichoderma 


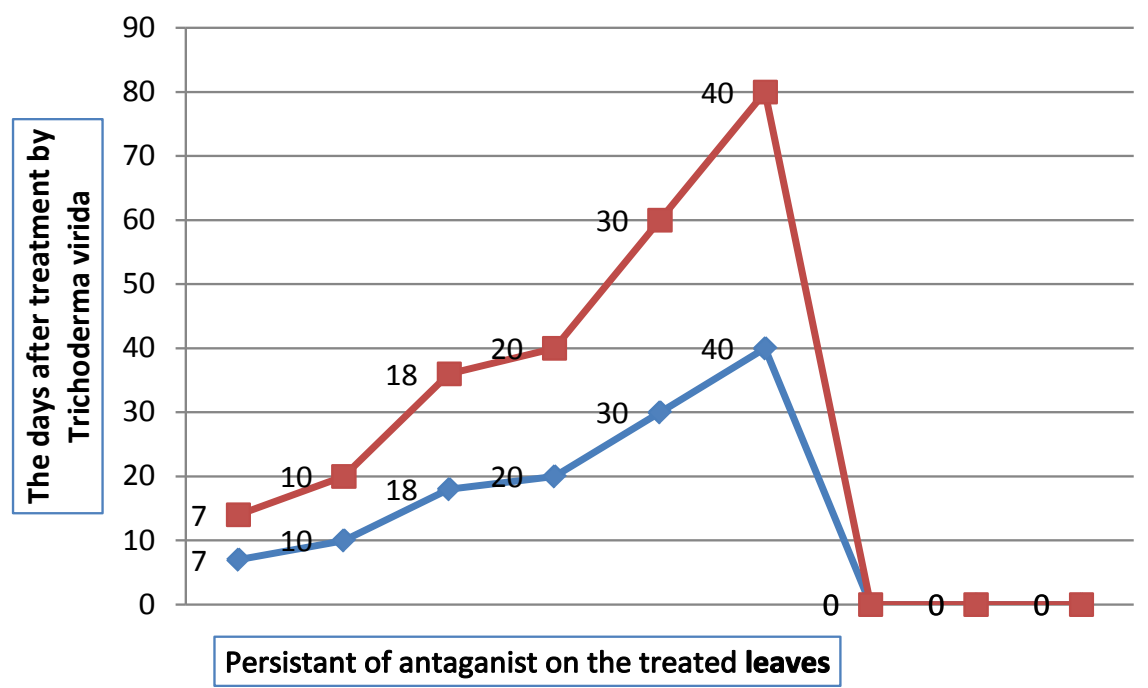

Figure 8. The shelf life of the Trichoderma viride antagonist's conidia on leaf surfaces of seedlings, 40 - 50 days after second treatment.
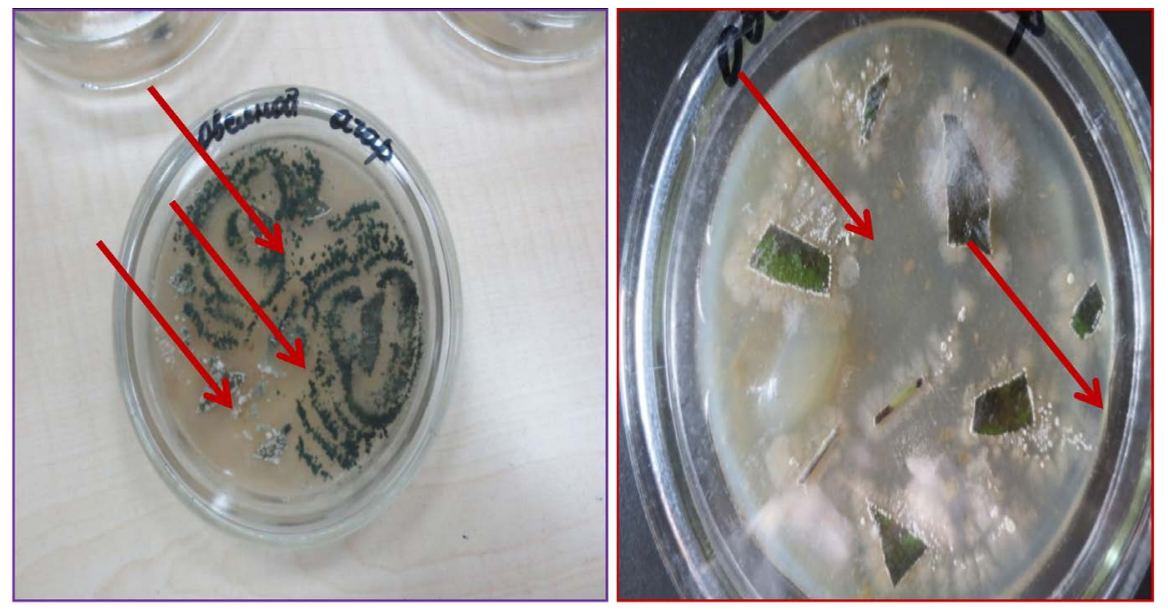

Figure 9. The leaf pieces taken from seedlings are shown by red arrows, around which the overgrown by colonies Trichoderma virida on the medium (the left) and by colonies Streptomyces sp. Cl-4 on the medium (the right).

virida; nevertheless, it prevented the progression of the disease on the leaves. Seedlings continued to grow new shoots and leaves 50 days after the second treatment (Figure 10(b)).

In the case of applying a biological product based on Streptomyces sp. C1-4; after the second treatment, Streptomyces sp. C1-4 spores remained on the leaf surfaces of seedlings for between 10 and 25 days. During this period, the spores of the antagonist agent grew slowly, but this encouraged dense actinomycetes growth around the leaves planted on the medium (Figure 11). Streptomyces $s p$. also produces the enzyme chitinase and a number of antibiotic substances, destroying the structure of the phytopathogens mycelium [24] [25] [26] [27].

\subsection{Orchard Experiments}

Two rows of three-year-old Aychurok apple trees were used to test the antago- 


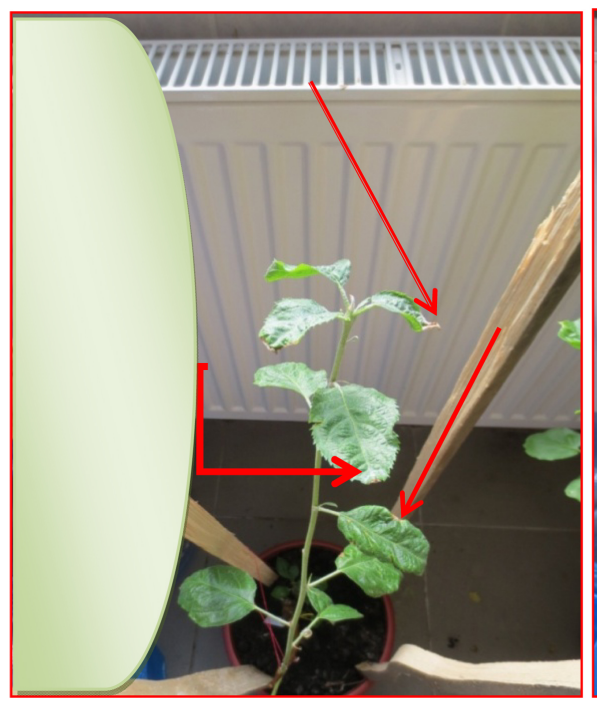

(a)

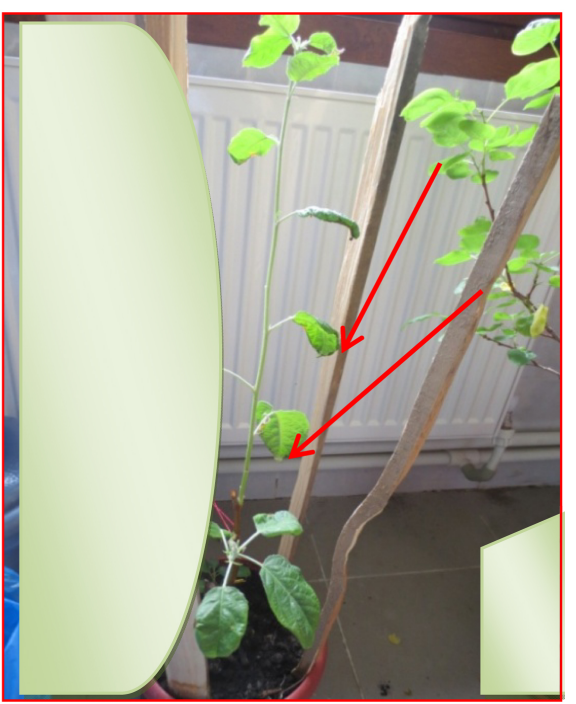

(b)

Figure 10. (a) The halted disease and recovered seedling leaves 40 days after the second treatment with Trichoderma virida $\left(1 \times 10^{6}\right.$ spores or cells $\left.\mathrm{ml}^{-1}\right)$; (b) The halted disease and recovered seedling leaves 50 days after second treatment with Streptomyces sp. C1-4.

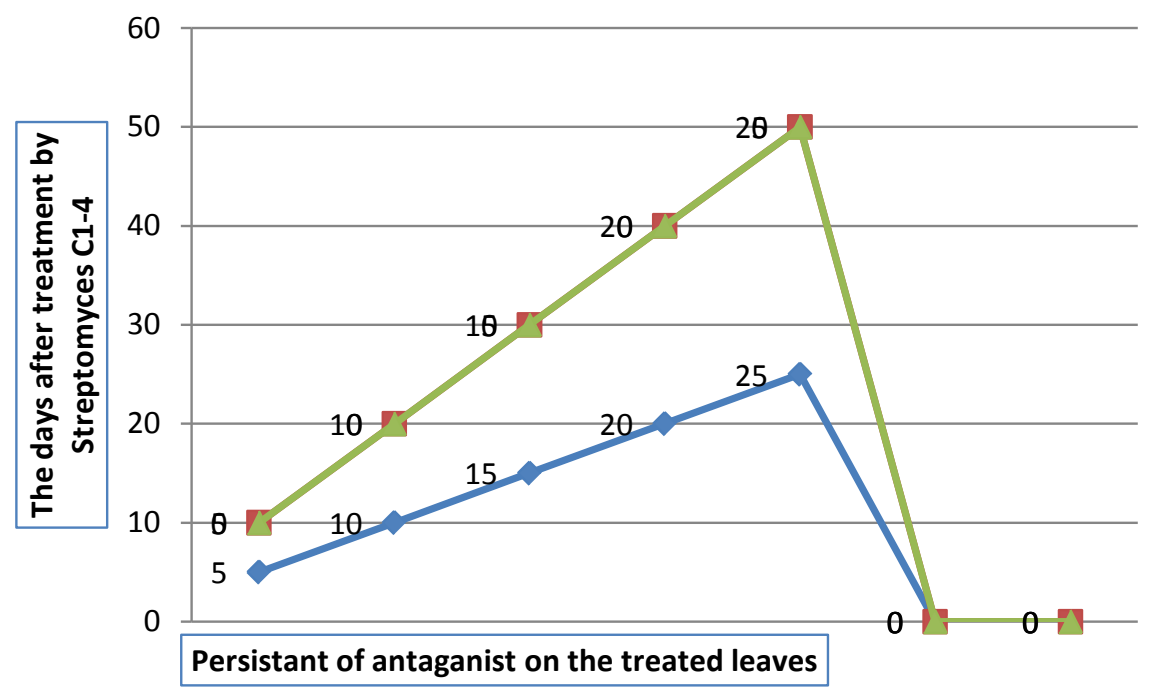

Figure 11. The shelf life of Streptomyces sp. C1-4 spores 25 days after the second treatment.

nists in the field. For each experiment, three trees were used (replicates). In the experimental and control plots, the trees were sprayed with a conidia suspension of the pathogen $V$. inaequalis $\left(1 \times 10^{7}\right.$ conidia $\left./ \mathrm{ml}\right)$ after the complete opening of the leaves and before flowering. After seven days, disease symptoms started to appear on the leaves of the apple trees (Figure 12).

Immediately after the appearance of these symptoms, the diseased leaves of trees in experimental plots were sprayed with a conidia suspension of Trichoderma virida $\left(1 \times 10^{7}\right.$ conidia/ml $)$ and a spore suspension of Streptomyces $\mathrm{sp}$. C1-4 $\left(1 \times 10^{8} \mathrm{spor} / \mathrm{ml}\right)$ until runoff at the bottom and upper side of the leaves. Treatment was carried out on a bright day after 17 hours; the air temperature 
was $18^{\circ} \mathrm{C}-20^{\circ} \mathrm{C}$. The disease development was monitored until 40 days after artificial infection was conducted. The damaged leaves and appearance of new leaves with disease symptoms were monitored. The development of the disease on leaves stopped 35 - 37 days after first treatment with the Trichoderma virida antagonist suspension, so that the damaged sections on the leaves did not change size further and the number of new leaves with diseased symptoms did not increase (Figure 13).

\section{Discussion}

Young leaves were quickly exposed to the pathogen, which penetrated their thin cell walls. The matured apple leaves demonstrated ontogenic resistance, because the pathogen growth was suppressed immediately after cuticle penetration and appearance of the disease's symptoms was delayed [4]. The strengthened cell wall and cuticular membrane, along with the sub-cuticular $\mathrm{pH}$ of such leaves, are speculated to play a role in governing such resistance.
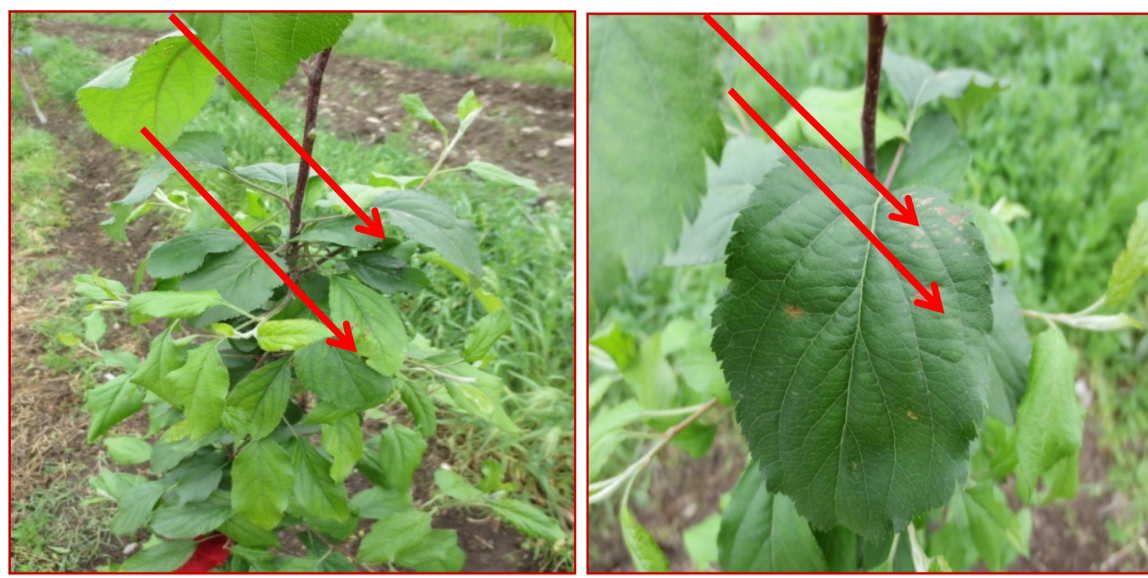

Figure 12. The appearance of necrotic lesions on the leaves of apple trees in the experimental plots after infection with the pathogen culture after seven days.
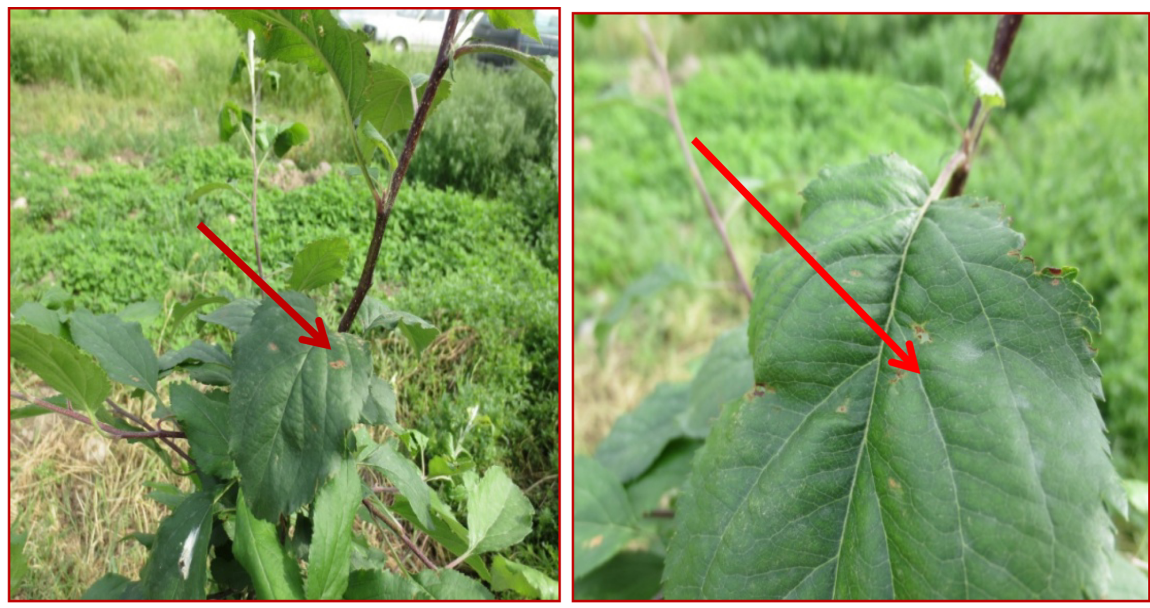

Figure 13. The damaged sections of the leaves did not change sizes and the number of new leaves with disease symptoms did not increase 35 - 37 days after first treatment with Trichoderma virida. 
Biological agents seem to contribute to the strengthening of protective responses and triggered a cascade of antipathogenic mechanisms on the part of the plant body. During the spring, observation of trees treated with Trichoderma viride revealed a sharp decrease in scab disease symptoms. According to Hinze and Kunz [11], the efficiency of the antagonistic fungi strongly depended on the timing of the application during the infection process. When these experimental tests were carried out, the climatic conditions were favourable for the development of both the pathogen and the antagonist. In mid-April, when the pathogen was used for artificial infection, humidity was $70 \%-80 \%$ and the air temperature reached 15 - 18 degrees; climatic factors were suitable for pathogen development on the leaves of apple trees.

After seven days, scab symptoms appeared on the leaves of trees in laboratory pots. After 10 days of infection, when the disease's symptoms had sufficiently developed, apple trees were sprayed with the culture of the antagonists. The climatic conditions were suitable for Trichoderma viride as fungus-antagonist (humidity, $70 \%-80 \%$, temperature, $18^{\circ} \mathrm{C}-20^{\circ} \mathrm{C}$ ). When using Trichoderma viride, the disease's progression stopped for 20 days after the first treatment. Necrotic lesions on leaves decreased; some of them started to show visible recovery and resumption of normal function. Trichoderma conidia remained on the surface of the leaves after a single application for $20-25$ days. If the weather in spring had been dry, different results would have been obtained. Nevertheless, these results provide great hope that a biological product based on Trichoderma viride could work as an effective agent to suppress the development of the pathogen in the early spring, when leaves start to show scab disease symptoms.

There was no sufficiently favourable condition for the development of the second antagonist agent, Streptomyces, as it prefers dry weather rather than wet.

Efficiency of Streptomyces sp. C1-4 was not high in field conditions, although the disease progressed more slowly than in the controls. Self-sustained survival of spores on the surface of the leaves was short; after 12 days, the spores were not detected. They were been superseded by other microorganisms and by pathogenic fungi in the epiphytic microflora of leaves. However, in dry years, the repeated use of this agent could be used to provide a biocontrol against scab disease.

The general conclusion of this study is that Trichoderma viride, used multiple times, could replace copper and other treatments and could be developed as an alternative strategy of treatment in organic orchards.

\section{References}

[1] An Overview of the Emergence and Spread of Major Pests and Diseases of Crops in the Kyrgyz Republic in 2015 and the Forecast of Their Appearance in 2016. Bishkek.

[2] Jamar, L., Lefrancq, B. and Lateur, M. (2007) Control of Apple Scab (Venturia inaequalis) with Bicarbonate Salts under Controlled Environment. Plant Disease and Protection, 114, 221-227. https://doi.org/10.1007/BF03356221

[3] Kollar, A. (1997) Aktuelle Forschung an dem bedeutendsten Erreger im Apfelanbau, dem Apfelschorfpilz Venturia inaequalis. Nachrichtenbl Deut Pflanzenschutzd, 
49, 131-136.

[4] MacHardy, W.E. (1996) Apple Scab, Biology, Epidemiology, and Management. St. Paul, Minn, USA, APS.

[5] Day, P.R., Boone, D.M. and Keitt, G.W. (1956) Venturia inaequalis (Cke.) Wint. XI. The Chromosome Number. American Journal of Botany, 43, 835-838. https://doi.org/10.2307/2438999

[6] Giraud, T., Gladieux, P. and Gavrilets, S. (2010) Linking the Emergence of Fungal Plant Diseases with Ecological Speciation. Trends in Ecology and Evolution, 25, 87395. https://doi.org/10.1016/j.tree.2010.03.006

[7] Gladieux, P., Guérin, F., Giraud, T., Caffier, V., Parisi, L., Didelot, F. and Lemaire, C. (2011) Emergence of Novel Fungal Pathogens by Ecological Speciation: Importance of the Reduced Viability of Immigrants. Molecular Ecology, 20, 4521-4532. https://doi.org/10.1111/j.1365-294X.2011.05288.x

[8] Smereka, K.J., MacHardy, W.E. and Kausch, A.P. (1987) Cellular Differentiation in Venturia inaequalis Ascospores during Germination and Penetration of Apple Leaves. Canadian Journal of Botany, 65, 2549-2561. https://doi.org/10.1139/b87-346

[9] Schumacher, C.F.A., Steiner, U., Dehne, H.W. and Oerke, E.C. (2008) Localized Adhesion of Nongerminated Venturia inaequalis Conidia to Leaves and Artificial Surfaces. Phytopathology, 98, 760-768. https://doi.org/10.1094/PHYTO-98-7-0760

[10] Vaillancourt, L.J. and Hartman, J.R. (2000) Apple Scab. The Plant Health Instructor. https://doi.org/10.1094/PHI-I-2000-1005-01

[11] Hinze, M. and Kunz, S. (2010) Screening of Biocontrol Agents for Their Efficacy against Apple Scab. ResearchGate Online.

http://www.researchgate.net/publication/266041890

[12] Kelderer, M., Casera, C. and Lardschneider, E. (2000) Zwei Jahre Erfahrungen mit der gezielten Schorfbekämpfung durch Oberkronenberegnung. In: Boos, M. and Betz, E., Eds., 9. Internationaler Erfahrungsaustausch über Forschungsergebnisse zum Ökologischen Obstbau, Weinsberg, FÖKO e.V., 5-11.

[13] Pfeiffer, B. (2008) Results from Scab Trials with Armicarb in the Years 2006 and 2007. 13th International Conference on Cultivation Technique and Phytopathological Problems in Organic Fruit-Growing, FÖKO e.V., ed. Weinsberg, FÖKO e.V., 41-46.

[14] Tamm, L., Amsler, T., Schärer, H. and Refardt, M. (2006) Efficacy of Armicarb (Potassium Bicarbonate) against Scab and Sooty Blotch on Apples. 12 th International Conference on Cultivation Technique and Phytopathological Problems in Organic Fruit-Growing, Weinsberg, FÖKO e.

[15] Trapman, M. (2008) Practical Experience with the Use of Baking Powder (Potassium Bicarbonate) for the Control of Apple Scab (Venturia Inaequalis). 13 th International Conference on Cultivation Technique and Phytopathological Problems in Organic Fruit-Growing, FÖKO e.V., ed. Weinsberg, FÖKO e.V. 68-75.

[16] Tripathi, P. and Dubey, N.K. (2004) Exploitation of Natural Products as an Alternative Strategy to Control Postharvest Fungal Rotting of Fruit and Vegetables. Postharvest Biology and Technology, 32, 235-245. https://doi.org/10.1016/j.postharvbio.2003.11.005

[17] Butt, T.M., Jackson, C.W. and Magan, N. (2001) Fungi as Biocontrol Agents: Progress, Problems and Potential. CABI Publishing, UK, 384. https://doi.org/10.1079/9780851993560.0000

[18] Burr, T.J., Matteson, M.C., Smith, C.A., Corral-Garcia, M.R. and Huang, T.C. (1996) Effectiveness of Bacteria and Yeasts from Apple Orchards as Biological Con- 
trol Agents of Apple Scab. Biological Control, 6, 151-157.

https://doi.org/10.1006/bcon.1996.0019

[19] van Leeuwen, G. and van Kesteren, H.A. (1998) Delineation of the Three Brown Rot Fungi of Fruit Crops (Monilinia spp.) on the Basis of Quantitative Characteristics. Canadian Journal of Botany, 76, 2042-2050.

[20] Mordue, J.E.M. (1979) Sclerotinia fructigena. CMI Descriptions of Pathogenic Fungi and Bacteria, 617, 1-2.

[21] Egorov, N.S. (1985) Antibiotics, a Scientific Approach. Mir Publishers, Moscow.

[22] Kohl, J., Molhoek, W., Groenenboorn-de Haas, L., Goosen-van de Geijn, H. and Eiben, U. (2012) New Approaches in Biological Control of Apple Scab. http://orgprints.org/

[23] Crawley, M.J. (1995) Methods in Ecology: GLIM for Ecologists. Oxford Blackwell Scientific Publications, London.

[24] Bolar, J.P., Norelli, J.L., Wong, K.W., Hayes, C.K., Harman, G.E. and Aldwinckle, H.S. (2000) Expression of Endochitinase from Trichoderma harzianum in Transgenic Apple Increase Resistance to Apple Scab and Reduced Vigor. Phytopatholy, 90, 72-77. https://doi.org/10.1094/PHYTO.2000.90.1.72

[25] Narayana Kolla, J.P. and Vijayalakshmi, M. (2009) Chitinase Production by Streptomyces sp. ANU 6277. Brazilian Journal of Microbiology, 40.

[26] Gupta, R., Saxena, R.K., Chaturvedi, P. and Viridi, J.S. (1995) Chitinase Production by Streptomyces viridificans. Its Potential in Fungal Cell Wall Lysis. Journal of Applied Bacteriology, 78, 378-383.

[27] Dahiya, N., Tewari, R. and Hoondal, G.S. (2006) Biotechnological Aspects of Chitinolytic Enzymes: A Review. Applied Microbiology and Biotechnology, 71, 773-782. https://doi.org/10.1007/s00253-005-0183-7

Submit or recommend next manuscript to SCIRP and we will provide best service for you:

Accepting pre-submission inquiries through Email, Facebook, LinkedIn, Twitter, etc. A wide selection of journals (inclusive of 9 subjects, more than 200 journals)

Providing 24-hour high-quality service

User-friendly online submission system

Fair and swift peer-review system

Efficient typesetting and proofreading procedure

Display of the result of downloads and visits, as well as the number of cited articles

Maximum dissemination of your research work

Submit your manuscript at: http://papersubmission.scirp.org/

Or contact aim@scirp.org 